\title{
CORTA-ME: ENSAIO SOBRE TRADUÇÃO
}

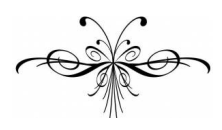

\section{LUIS FERNANDO PROTÁSIO}

Resumo: Como o ensaio de um espetáculo cuja estreia está, ainda, por vir, este exercício acompanha, em estilo experimental, a cena da tradução da escritora e tradutora canadense radicada em Paris Nancy Huston. O objetivo é apresentar a fundação de uma ética que, ao cortar a lógica da repetição alienadora de determinado atributo (o “outro", a “letra”, a “diferença”...), eleva o intervalo do desejo, transformando-se ela mesma numa tarefa sempre - ainda - por vir.

Palavras-chave: tradução e ética; autotradução; devir.

\begin{abstract}
Resembling the rehearsal of a spectacle whose debut is yet to come, this essay follows, in an experimental style, the translation scene of Paris-based Canadian author and translator Nancy Huston. The aim is to exhibit the foundation of an ethics which, by cutting up the logic of an alienating repetition of a given attribute (the so-called "other", "letter", "difference”...), enhances the interval of the desire, becoming itself a task always [yet] to come.
\end{abstract}

Keywords: translation and ethics; selftranslation; becoming. 
Como a árvore de Nietzsche, o texto tradutivo seria exemplar e mais paradigmático de uma ciência do devir.

Alexis Nouss

Viver-não, viver-sem, como viver sem conviver, na praça de convites?

Carlos Drummond de Andrade

\section{A cena da tradução em Nancy Huston}

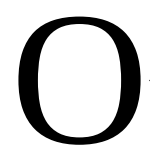
abandono pela mãe, além de representar um momento de ruptura que terá causado um trauma em Nancy Huston, escritora e tradutora canadense radicada na França desde a década de 1970, funciona também como um momento de deslocamento, de conversão e de transição a partir do qual será fundada a própria possibilidade da narração e da tradução do “eu”. Com efeito, tanto o ritual da alienação do eu mesmo como cena espetacular da tradução quanto a teatralização de seu trauma, narrado e reinventado como (e na) fábula de uma auto-bio-grafia opera como uma dobra “esquizofrênica” (RONELL, 1989) que será repetida (iterada, no sentido de ensaiada, de reatualizada) na escrita da autotradução. Essa reatualização, por seu turno, justifica a transferência (e a transmissão, Übertragen, no sentido clínico) do sintoma inscrito (somatizado ${ }^{1}$ ) no corpo próprio [físico, zoé] para o corpo pulsional da língua. É no ensaio do adiamento, da indecidibilidade, da incoerência e do absurdo que a tradução que Huston inventa (e encena) a possibilidade de restituir o corpo (da mãe, da língua materna, do "eu” que ainda não entrara no mundo simbolizado...). “Aporia” e "desorientação” (Huston, 1999/2002) fundadas no acordo de que o território do "eu” (e, portanto, da memória, do arquivo, desse "eu”) não é senão um espaço habitado pelo outro (Unheimlich) manifestam-se, dessa forma, espetacularmente no trecho de ... et la plume/... And the Pen, ensaio incluído no volume (alegadamente) autobiográfico Nord perdu (1999) / Losing North (2002). Vejamos:

Et pourquoi Kundera a-t-il perdu son sens de l'humour en abandonnant le tchèque? Ainsi de suite... Qui sommes-nous, alors? si nous n'avons pas les mêmes pensées, fantasmes, attitudes existentielles, voire opinions, dans une langue et dans une autre? Aporie, une fois de plus. Déboussolant, vous comprenez.

C’est par où, le nord? (1999, p. 52, ênfase no original)

Why did Kundera lose his sense of humor when he started writing in French? Und so weiter $^{2}$... Who are we, in other words, if we don't have the same ideas, the same fantasies, the same existential outlooks or even the same opinions in one language as in another?

\footnotetext{
${ }^{1}$ Para uma revisão crítica das relações entre corpo, tradução e somática, ver Nascimento e Silva (2009).

${ }^{2}$ Do alemão, “E assim por diante”.
} 
Oh dear, I feel a bit lost again.

It's disorientating, you see what I mean?

Which way is up? (2002, p. 49, ênfase no original) ${ }^{3}$

Numa tentativa de “comparar o incomparável” (DETIENNE, 2000), isto é, de realizar, por gozo estético e protocolo acadêmico a aproximação dos dois excertos citados, proponho colori-los com dois momentos de narração - justamente um momento de "aporia" e um de "desorientação". Esse gesto, que é antes de tudo um gesto de citação, demanda, entretanto, um espaço enunciativo experimental que, como todos, correrá sempre o risco de "ser excessivo" (o que se chamará, inevitavelmente, overreading, misreading ou, até mesmo, contingencialmente, sobredeterminação [Über-determinierung]). Mas o que é a tradução senão uma experiência do excesso [über] de crítica, um exagero [over] de leitura e uma incoerência [mis-] do transbordamento de uma língua em outra, de uma língua pela (através e em favor de) outra - em outras palavras, um gesto de negação. Se isso justifica o risco (o corte), que se 0 assuma.

O primeiro momento de narração, que aproximo de um momento de "aporia", diz respeito ao lugar que o abandono ocupa nos textos recortados: enquanto em francês (língua de adoção de Huston ${ }^{4}$ ) o abandono ata-se à língua materna (à nomeação da língua de Kundera - "le tchèque" -, espaço familiar onde o chiste impera), em inglês (língua materna de Huston), esse mesmo abandono é rasurado para dar lugar, justamente, à língua de adoção (tanto de Huston quanto de Kundera): o francês. Em outras palavras, em francês, Huston nomeia a língua abandonada (a língua mater de Kundera, o tcheco) a partir de um sistema convencional de referencialidade que aponta para o mundo empírico e ilumina (éclat) uma "verdade" que, todavia, não serve de guia, mas desorienta; em inglês, contudo, o ato de nomeação (logo, o sistema convencional de referencialidade instituído pelo gesto divino) é rasurado precisamente em função da nomeação da língua de adoção, ou seja, da língua imprópria, escolhida (a nomeação do francês).

E é essa escolha, que leio como corte, que introduz o segundo momento de narração: a "desorientação", marcado, no texto em inglês, pelo sintagma alemão "Und so weiter" [e assim por diante]. Ao sobrevir na língua inglesa, na língua da mãe, em cujo corpo opera um corte, o sintagma estrangeiro reatualiza o abandono inscrito no texto em francês ("Et pourquoi Kundera a-t-il perdu son sens de l'humour en abandonnant le tchèque?”), levando-o a um outro nível, marcado pelo compasso da violência, e interrompendo quaisquer possibilidades da restituição encenada no primeiro plano (“C’est par où, le nord?; “Which way is up?”). Essa interrupção, por sua

\footnotetext{
${ }^{3}$ Mas por que Kundera perde o senso de humor quando abandona o tcheco e começa a escrever em francês? Well, well... Em outras palavras, quem somos nós, então, se não temos os mesmos pensamentos, os mesmos fantasmas, as mesmas atitudes existenciais ou até mesmo opiniões similares em mais de uma língua? Aporia desoladora. É desconcertante, percebe? Para que lado é o norte?” (tradução minha)

${ }^{4}$ Fundamental é sublinhar a natureza eminentemente dupla dessa adoção: indicada por um gesto, ele mesmo, replicado (“de adoção”/“de Huston”) - um ensaio [rehearsel], portanto -, a adoção diz respeito tanto ao "ator” [performer], à "língua” (a língua francesa acolhe Huston) quanto ao “personagem” [character] “Nancy Huston” (Huston escolhe a língua francesa).
} 
vez, é reintroduzida pela pergunta “who are we” [quem somos nós] que reforça a espetacularização do trauma em cena.

Nesse sentido, o abandono, como território de rebento ${ }^{5}$ da tarefa de tornar público o reengendramento de si mesmo (self, Selbst) em solo estrangeiro, pelo fato de reatualizar a “competição interminável com a mãe”, como narra Kristeva citada por Huston (cf. HUSTON, 1995), antes de ser renúncia da língua materna, é desejo de enfrentamento que suspende as responsabilidades, enxertando-se em um estádio ${ }^{6}$ do que chamarei de devir-ético o qual comparecerá na persistência da língua materna. Em outras palavras, por publicar o abandono, o que há é não uma renúncia, mas um desejo hesitante de enfrentamento - desejo materializado na tradução e na obstinação em traduzir os próprios textos, como demonstra a (famosa) declaração de Huston que Klein-Lataud (1996) recupera: "Não confiava em ninguém para fazer a tradução. Quando a primeira versão [do romance Plainsong] foi concluída, eu a reescrevi em francês” (LAURIN, 1993, apud KLEIN-LATAUD, 1996).

Se é assim, o que a tradução conserva é também aquilo que nela resta como uma falta, estruturalmente incompleta apesar de quaisquer movimentos de significação ou de escritura (texto, crítica, retradução...). E essa falta está para sempre instalada no devir de um futuro apenas garantido pelo ato de rememoração, pela iterabilidade de um projeto impossível, porém necessário que abriga em sua possibilidade a tradução como acontecimento que irrompe (rebenta) no intervalo em que se erige aquilo que ela conservará.

Como, então, recuperar esse ato de rememoração, essa iterabilidade para finalmente abandonarmo-nos, nós, espectadores, ao espetáculo da tradução em contínuo ensaio na cena de tradução praticada por Nancy Huston? Recuar da tradução em cena seja, talvez, o primeiro passo rumo ao futuro preservado no arquivo a ser reensaiado, reinterpretado, reinventado em cada ensaio de apresentação [performance]. É isso que faço nesse momento.

\footnotetext{
${ }^{5}$ Remeto, aqui, à canção “Rebento”, letra de Gilberto Gil que se tornou clássico da MPB na performance de Elis Regina, em especial no Montreux Jazz Festival, gravado em 1979 e lançado em LP e CD pela gravadora WEA em 1982. Interessante notar que, embora seja “o ato, a criação, o momento”, gesto primordial e, portanto, convencional que responde pela "origem”, como fica claro na palavra alemã Ursprung (ur: matriz, princípio, primevo; sprung: salto, pulo, mas também hiato, falta), “rebento” pode ser lido, também, "simplesmente” como lavra, "reação”, presente acidental e, assim, oposto a qualidades de “essência” e "substância” (cf. HOUAISS). Essa leitura permite, nesses termos, lermos “rebento” também e fundamentalmente como “repetição” (re-bento) de um momento num “só-depois” [Nachträglichkeit, aprèscoup, no saber da Psicanálise]. Assim lido, esse movimento de significação interditaria, então, quaisquer possibilidades de felicidade ou sucesso das chamadas teorias descritivas da tradução. É nesse sentido que a tarefa (do tradutor) torna-se desejo para além (desejo é sempre “para além”, au-delà] de renúncia, como mostrarei mais adiante neste ensaio.

${ }^{6}$ Estágio, mas também anfiteatro.
} 


\section{A cena recuada [aporia]}

\subsection{O espaço dobrado da ética}

Em uma leitura informada pelo pensamento continental (notadamente o pensamento francês recolhido, pela leitura norte-americana importada por alguns setores da academia brasileira, no questionável conceito de "pós-estruturalismo"), a problemática da assinatura e do nome próprio, inerentes aos discursos convencionais e, portanto, hegemônicos sobre a prática da autotradução surge como uma linha de fuga capaz de permitir o rompimento com o fluxo do bilinguismo (ou da condição bilíngue), rompimento cujo maior impacto é a divulgação dos limites teóricos dos discursos contemporâneos sobre a tradução, de modo específico, e sobre a linguagem, de modo amplo. De acordo com essa leitura, a autotradução manifesta a interdição do sucesso (do speech act) dos modelos de pensamento em que a ética (sempre "adjetivada", sempre da ordem de uma atribuição) comparece como um espaço institucionalizado (1) de sacralização da diferença (monopolizada pela ideia de mestiçagem, de "apropriação" e de violência) e (2) de comemoração da exceção (capitalizada pela ideia de recriação, de "letra" e de teleologia messiânica). Deflagrando a crise própria da contemporaneidade, esse mecanismo de interdição projetaria uma dobra no espaço da ética (no ethos), suspendendo sua função legisladora habitual cuja possibilidade, assim, apenas poder-se-á delinear, como espectro, no horizonte do devir ${ }^{7}$.

Chamarei de ética de essa ética da ordem da atribuição que os discursos sobre a tradução projetam na tradução (no corpus da tradução) - a ética "da letra" (BERMAN, 2007), a "ética da diferença” (VENUTI, 2002), a "ética da apropriação" (CARNEIRO, 2008) - e de ética a a ética que delineia (no corpo da tradução) uma dobra no espaço do ethos clássico (isto é, da repetição como reprodução, acontecimento habitual) e suspende o suplemento, então devir, iterabilidade pura (ou seja, repetição como transformação, evento possível, condição de possibilidade). Embora ambas constituam um performativo de promessa balizado pelo sucesso ou insucesso, felicidade ou infelicidade (AUSTIN, 1975) de sua realização, a primeira funciona como um mecanismo de interdição soberana (portanto, disciplinar), ao passo que a segunda atualiza um mecanismo de interrupção, de corte e cesura cujos desdobramentos impedem, como proponho abordar em seguida, a demarcação de um campo disciplinar já que esse só pode existir como possibilidade, a posteriori ${ }^{8}$.

\footnotetext{
${ }^{7}$ Nesse sentido, a tradução como “ciência do devir”, como sugerido por Alexis Nouss (2012b), ganha contornos ainda mais sintomáticos.

8 Talvez a alegoria mais espetacular dessa natureza de "a posteriori” da iterabilidade pura que desloca inclusive o mecanismo da promessa tal como lida por Austin (1975) seja a peça de Samuel Beckett, Esperando Godot: nela, o a posteriori (convocada pelo espectro “Godot”) não chega sequer a ser uma personagem, mas simplesmente um nome emprestado ao título e cujo papel em cena é remetar à própria espera da cena (em que supostamente aparecerá) compulsivamente retardada, adiada, diferida.
} 


\subsubsection{A ética de}

Marcada pelo signo do pertencimento ${ }^{9}$ (traço do genitivo), a ética de opera de acordo com uma dinâmica jurídica de soberania que se apropria da responsabilidade de vigiar a tradução e de garantir que ela siga sendo "tradução". Em outras palavras, um mecanismo cujo papel central é legislar sobre a tradução, certificando que ela não coloque à prova o estatuto do texto com que se relaciona (se entendermos que a tradução fosse relação, como sugere Cardozo [2007, 2009] a partir de Berman [1995]) e que não revolucione a estrutura institucional (relicário ou bestiário positivista), mesmo que, para isso, paradoxalmente, seja necessário inventar um espaço institucional próprio, como tem sido o foco dos discursos sobre a tradução desde a década de 1980.

Entretanto, considerada de uma perspectiva crítica, isto é, de uma perspectiva que considera o texto em uma história (ou, em outras palavras, que considera a dimensão da obra), seria lícito perguntar se a ética de que informa os discursos sobre a tradução não encarnaria (no sentido de "dar corpo a”) a responsabilidade como uma fidelidade à matriz de pensamento ocidental clássico ("logocêntrico”, diria Arrojo, 1992; 2007) em que a tradução (o traduzir) é, antes de tudo, uma virtude que afiança (que dá fé) ao corpo sagrado, mágico e legítimo que, ao emergir, dá-se ao conhecimento (Ur-sprung, origem). Isso significa dizer que a responsabilidade, percebida como questão que funda a problemática da ética em tradução (ponto, aliás, em que os discursos que a debatem concordam), não se limita a desdobramentos sociais, políticos e culturais, como declaram as posturas tanto pós-coloniais quanto pós-modernas assumidas pelos discursos sobre a tradução empenhados em uma crítica da ética em tradução, mas tenciona o mecanismo de double bind do interdito (proibido/proibição) que Derrida (2002) leu na lei em Kafka.

Esse mecanismo, que inscreve num mesmo espaço nome (substantivo) e atributo (objeto), reencena, no lugar da ética, a "Lei” da tradução que, segundo a leitura de Siscar (2000),

combina num mesmo movimento a proposição da regra e a proibição da regra; a reiteração de seu traço torna-se concomitante à sua retirada (um re-trait, cuja articulação dupla é um dos movimentos fundamentais da desconstrução derridiana). A lei da tradução como desvio é assim desvio em relação à própria lei. Em outras palavras, se a tradução é concebida como uma leitura, se a tradução é uma espécie de crítica (se quisermos pensar no conhecido ensaio de Haroldo de Campos, "Da tradução como criação e como crítica”), é preciso lembrar que leitura e crítica são igualmente traduções: é sua lei. (p. 62, ênfase no original)

Ao fundir leitura e crítica na lei da tradução, cuja dupla tarefa da gênese e da passagem ao discurso (SISCAR, 2000, p. 60) ganha força espetacular ${ }^{10}$ na prática da autotradução, o que se coloca diz respeito não apenas ao caráter crítico da tradução tal

\footnotetext{
${ }^{9}$ Não é por acaso, aliás, que a noção de pertencimento seja tão cara aos chamados Estudos Culturais, em cujos discursos (como em Hall [2002]) ganha uma função redentora que, de fato, não enunciam em essência. Afinal, segundo o adágio derridiano já consagrado, “la langue n’appartient pas”.

${ }^{10}$ Aqui, especialmente no sentido de encenação pública (cf. Houaiss).
} 
como o entenderam Haroldo de Campos (1976) e Antoine Berman (1984) informados pelo projeto de tradução do chamado Romantismo alemão, mas, principalmente, o que concerne o double bind indecidível de uma "ética imanente"11 (VERAS, 1997) ao ato de tradução. Esse double bind, por sua vez, publica (torna público) menos um "lugar entre” (um lugar especial de relação e de convivência) e mais um "não-lugar” (um lugar de expropriação e resistência, um "limbo") em que, nas palavras de Veras (1997), “a singularização não tem certamente nenhuma garantia de manutenção, não podendo vencer de uma vez por todas, nem transformar-se num modelo (um ideal de singularidade)” (p. 333).

É esse caráter de indecidibilidade e indeterminação o que torna o double bind ético inscrito na prática da autotradução ao mesmo tempo resistente à apropriação pelos correntes discursos sobre a tradução e hostil à possibilidade de que se sustente teoricamente uma ética da ordem do atributo (como sugerem Berman, Venuti e seus seguidores), colocando-a em eterno adiamento. Tal posição, por seu turno, interdita o trabalho teórico nos moldes que ele tem assumido contemporaneamente nos Estudos da Tradução que, de acordo com Siscar (2000):

encontra-se assim numa situação problemática em relação ao conteúdo positivo de suas afirmações, ainda que proceda de maneira cuidadosa e ainda que prime pela capacidade de explicitação de suas estratégias. [...] Se a lei da tradução não pode ser generalizada num único traço, a lei da tradução também não pode ser delimitada e resgatada com um único traço. (p. 62)

Se, portanto, a lei da tradução é, de certa maneira, o double bind do interdito que concretiza a tradução, ela não reintroduz na cena o valor da responsabilidade, mas dobra o espaço da responsabilidade, tornando-a antes uma questão de resposta, de envio, “de atenção ao chamado de um outro” (SISCAR, 2000).

Essa resposta e esse envio, todavia, mobilizam uma responsabilidade que tem mais a ver com “desejo” (de um futuro por vir, isto é, por ser construído, como sugerem Deleuze e Guattari, 1975) do que com a "justiça", com o "fazer justiça (ao outro)", como teria pensado Ricoeur (1990). Nesse sentido, se, sobre a "lei”, predomina o “desejo” ou se, ainda, “lá onde acreditava-se haver a lei, há de fato, desejo e tão somente desejo"12 (DELEUZE \& GUATTARI, 1975, p. 90), é porque justamente o que a responsabilidade como resposta impõe é o território do devir [devenir], isto é, o território prometido não por uma imitação ou por uma conformação a um modelo (cf. DELEUZE, 1998), mas um território de suspensão, de risco ou de adiamento de uma ética que interrompe a lei do "fazer justiça ao outro” (a ética de). Essa interrupção, a meu ver, ocorre em virtude de um mecanismo de "hifenização cessante" (cf. DEÂNGELI, 2012) ao qual vinculo, aqui, a ética a, cujos aspectos apresentarei no tópico seguinte.

\footnotetext{
${ }^{11}$ Veras (1997) define a ética imanente nos seguintes termos: “[...] inseparável desse trabalho [teórico], [uma ética imanente] caminharia junto com ele, o que significa que não está pronta, que deve ser construída de cada vez” (p. 328)

12 “là où l’on croyait qu’il y avait loi, il y a en fait désir et seulemente désir.”
} 


\subsubsection{A ética a}

Fundada na ausência sempre adiada, sempre por vir de um destinatário que, como o tradutor vinculado à sua tarefa por força de uma promessa feita, da palavra dada, a ética que chamarei de ética $a$ ata-se irreversivelmente a um chamado, a uma chamada, recebe uma ligação encaminhada pelo outro e que, como "outro", entra em sua casa, de surpresa, através da abertura (da máquina, pelo fio eletrizado do telephone, na leitura de Ronell, 1989). Esse espaço esvaziado onde pontes não são necessárias (por mais que se insista em construí-las) e que se eleva entre o que Derrida (2000) chama "a tradução mais relevante" e "a menos relevante possível" diz respeito ao espaço de adiamento inaugurado pela letra "a" e publicado tanto no silêncio insuperável da différance derridiana quanto na cesura insustentável do objet petit a lacaniano.

Esse vazio, esse não-lugar que responde pelo esgotamento que dobra a ética e materializa um negativo (no sentido dialético) cumpre uma função estrutural na medida em que publica a autocontradição da autotradução e instaura uma possibilidade criadora, uma contingência transformadora, como sugere o mecanismo de esquecimento inerente à língua discutido por Heller-Roazen (2010).

Nesse sentido, a ética $a$, como espaço de possibilidade e intervalo estrutural (como espaçamento), implica a construção do suplemento, então oferecido ao outro (o "intérprete", o ouvinte, o leitor...) sempre como um "presente envenenado" (gift/Gift). Assim, o problema convocado pela ética a é, igualmente, o problema invocado pelo chiste. Como aponta Veras (2009),

(...) o chiste se traveste justamente nesse modo de se dizer sem se dizer, em sua forma esquiva de dar passagem ao desejo, manifesto no que Freud chamou de uma "vestimenta chistosa" sob a qual não adianta buscar a verdade nua e crua. O chiste se dá a ler como ruptura, interrupção, como uma descontinuidade, uma vacilação na relação da língua com ela mesma, com o sistema, para lembrar Saussure, que tem sua "ordem própria” (1972: 31) abalada pelo corpo estranho, impróprio, que poderia ser excretado pelo riso, pelo rubor, pela dor, ou, mais além do corpo, pela fixação do que dele restou em uma tipologia. (p. 2-3)

Ora, se o que a tradução informa (realiza) é justamente a interrupção e o equívoco, o que ela envolve é, mais do que a experiência dos limites (e certamente mais do que a fronteira das línguas com que os estudos descritivos da tradução, talvez excessivamente, preocupam-se), uma questão de resposta e endereçamento impossíveis de uma ética deslocada pelo performativo da promessa que, nesse sentido, será continuamente uma promessa infeliz: sempre interrompida pelo risco (no duplo sentido do termo) que adia ou rasura seu cumprimento ao mesmo tempo em que ata [bind] ou enxerta, como um "traço-de-união" (DEÂNGELI, 2012), esse cumprimento ao performativo, tornando-o, assim, cicatriz ou tatuagem, mas, de qualquer forma, arquivo esquecido nos bastidores de uma encenação (a cena da tradução que o busca recuperar) que não cessa jamais de se ensaiar. É tal mecanismo que o tópico seguinte, em off, procura narrar. 


\section{A cena ex-crita [desorientação]}

Afirmei que a prática da autotradução é o espaço dobrado da ética fundada no acontecimento habitual (portanto, passível de iteração ${ }^{13}$ ) de traços privados em espaços públicos (institucionais) legislados. Isso significa que a prática da autotradução diz respeito ao território em que a promessa (isto é, o performativo) instaura uma rasura hesitante que não cancela, mas corta sua própria possibilidade. Em outras palavras, o que em autotradução se encena é não o desaparecimento da questão da origem (presumida correntemente habitar a mesma entidade biográfica), mas a alienação da origem, ao mesmo tempo esquecimento e arquivamento, abandono do rastro da origem e da origem como rastro.

Tendo em vista essas considerações, é possível retomar a cena da tradução em Nancy Huston sob uma perspectiva articulada em três aspectos em off: esquecimento, arquivo e abandono. Para isso, porém, é necessário antecipar uma dupla conclusão de leitura, em parte introduzida no tópico anterior e que é a seguinte: o esquecimento fundamental, tal como o entende Heller-Roazen (2010), não apenas marca, em certo sentido, o nascimento da matriz de pensamento ocidental que informa, ainda, os discursos contemporâneos sobre a tradução, mas, sobretudo, anuncia o acontecimento da tradução. Nesses termos, o que esse "ato de esquecimento" aciona é não apenas a possibilidade de adquirir uma língua (de entrar na língua), como aponta brilhantemente Heller-Roazen (2010), mas também a própria possibilidade de entrar no jogo simbólico, de se transformar em "eu" e, assim, fazer parte do mundo civilizado (cf. VERAS, 2008). Nesse sentido, esse esquecimento fundamental constitui, ainda e sobretudo, um lugar de falta estrutural que, como explica Veras (2008), "é causa de desejo (preenchimento), cuja realização encerraria o jogo” (p. 119).

Sendo falta estrutural sempre situada a priori, esse esquecimento não pode, portanto, representar (no sentido de tornar novamente presente) um passado que estaria conservado na memória (numa memória ancestral) e que corporificaria a autoridade e a Lei no sentido paradoxal da soberania que Agamben (2003) investiga. Dito de outra maneira, esse esquecimento fundamental é um rastro, no sentido que Derrida (2008) entende esse termo, o que quer dizer que "não é somente a desaparição da origem, ele quer dizer [...] que a origem não desapareceu sequer, que ela jamais foi construída a não ser por uma não-origem, o rastro, que se torna, assim, a origem da origem" (DERRIDA, 2008, p. 75).

Essa leitura do esquecimento fundamental como rastro permite dizer que ele rompe (abandona) a cadeia de iteração, repetição como reprodução do passado (que, nesse sentido, não pode mais ser sustentado, que não há) e aciona a iterabilidade, repetição como transformação, sobretudo do futuro [l'avenir]. É nesse ponto que Derrida (1995) insiste, por exemplo, em Freud e a cena da escritura, ao afirmar que

\footnotetext{
${ }^{13}$ Como explica Derrida (1991), não se deve confundir "iterabilidade” com "iteração": enquanto essa diz respeito à repetição (como reprodução), aquela concerne a possibilidade estrutural de repetir ou ser repetida. De certa maneira, Derrida está dizendo que essa é a confusão fundamental da leitura que Searle teria feito não apenas no que dizia respeito a sua leitura de Austin ("Signature, Événement, Contexte", 1972), mas, em certo sentido, também do próprio ensinamento de Austin.
} 
não existe texto presente em geral, nem mesmo há texto presente-passado, texto passado como tendo sido presente. O texto não é pensável na forma, originária ou modificada, da presença. O texto inconsciente já está tecido de traços puros, de diferenças em que se unem o sentido e a força, texto em parte alguma presente, constituído por arquivos que são sempre já transcrições. Estampas originárias. Tudo começa pela reprodução. Sempre já, isto é, depósitos de um sentido que nunca esteve presente, cujo presente significado é sempre reconstituído mais tarde, nachträglich, posteriormente, suplementarmente: nachträglich também significa suplementar. (p. 200)

Se, portanto, a possibilidade da entrada no jogo da língua, do simbólico e da lei só há por ocasião do corte violento que imprime o esquecimento fundamental de que fala Heller-Roazen (2010), do arquivamento e do abandono de um "reino ilimitado" que deve ser renunciado, sob pena de sermos interditados da civilização (FREUD, 2012 [1913]), não seria impertinente, então, aproximá-la da questão do arquivo discutida por Derrida em Mal de arquivo: uma impressão freudiana (2001). Nesse livro, Derrida afirma que o arquivo ou, antes, “a questão do arquivo”, não diz respeito ao passado, nomeando, assim, "um conceito do qual nós disporíamos já sobre o tema do passado, um conceito arquivável de arquivo” (2001, p. 50). Pelo contrário, Derrida sugere que o arquivo é “a própria questão do futuro, a questão de uma resposta, de uma promessa e de uma responsabilidade para amanhã” (idem, p. 51).

Sendo a própria questão do futuro ${ }^{14}$, igualmente o arquivo não motiva a repetição (compulsiva) do passado, de uma lembrança ou da memória [Erinnerung] como mecanismo de purgação, mas, pelo contrário, possui um caráter re-construtivo (suplementar) que implica sempre um a posteriori. Esse a posteriori, esse devir projetado não pelo passado, mas pelo futuro, de acordo com Vladimir Safatle (2012), participa, de maneira fundamental, da cena em que Freud inscreve o papel do esquecimento, vinculado à transferência [Überführung ${ }^{15}$ ], na prática clínica. Daí a razão de, ainda segundo Safatle (2012), Freud (2010 [1914]) estabelecer um paralelo entre repetição e esquecimento, de um lado, e recordação (Safatle opta por “rememoração”) e cura, de outro.

\footnotetext{
${ }^{14}$ Sobre a questão do futuro, remeto ao livro fundamental da filósofa francesa Catherine Malabou, The Future of Hegel: Plasticity, Temporality and Dialectic (translated by Lisabeth During, Routledge: New York/London, 2005), em especial o prefácio de Jacques Derrida (“A time for farewells: Heidegger [read by] Hegel [read by] Malabou").

${ }^{15}$ Interessante ressaltar que o termo alemão para transferência, Überführung, indica um movimento de passagem [Überführung significa "translação"; führung, "condução"] e, nesse sentido, conserva uma relação bastante peculiar com o discurso tradicional sobre a tradução que a aproxima [Übersetzung] ao mecanismo da metáfora e que responde pela clássica imagem de tradução como ponte ligando culturas, línguas e podendo, portanto, ser atravessada.
} 


\section{Replay, reprise: devir-ético, devir-original}

\subsection{Da tarefa-renúncia à tarefa-desejo de Nancy Huston}

O desejo arquivado na repetição (iterabilidade) do trauma do abandono pela mãe funciona em Huston como um corte que realça o mecanismo de deslocamento, conversão e passagem. É, portanto, um acontecimento que tem lugar (a lieu) no embate, na resistência, na crítica, no intervalo que promove, justamente, a tradução (no sentido mais amplo que esse termo possa significar). Assim, ter lugar (avoir lieu) é reafirmar o espaço de passagem e de espaçamento [espacement] de um “entre” a todo instante variável, pois o que está "entre" é justamente o que o tradu(au)tor insere ou remove na tradução, a vírgula que silencia, trunca e faz parar ou o "traço-de-união" que, nesse sentido, pode ser tanto “um movimento de 'hifenização', nos interstícios de alguma identidade por vir” (DEÂNGELI, 2012, p. 76), reafirmando a possibilidade de restituição ou de repetição (reprodutora), quanto um corte ou cesura que interrompe as pretensas unidades, as fantásticas estabilidades e as utópicas significâncias, impondo o abandono unicamente no não-lugar do desejo de repetição (transformadora).

É essa "hifenização cessante", colocada em funcionamento no ensaio En français dans le texte ${ }^{16}$ (1995), que inaugura, de um só golpe, os momentos de "aporia" e de "desorientação" implicados no texto de Nancy Huston (1999/2002) como sugeri no início desta peça. É precisamente esse momento duplo que servirá, aqui, de bom momento para o retorno (a repetição, o replay) da cena da tradução colocada em standby.

Em certa passagem, lemos:

C'est juste une explication, juste l'histoire que je me raconte pour comprendre ma vie, pour pouvoir m'endormir le soir : chacun transforme sa vie en histoire pour la rendre compréhensible, avalable. Donc, en matière de langue maternelle, quand j'avais six ans, elle a disparu. Ma mère. Avec sa langue dans sa bouche. MaryLouise, elle s'appelait, s’appelle encore. Et aussi : Mommy, Mom, Mother. Elle a été immédiatement remplacée par une jeune émigrée allemande du nom de Maria. Mutter. Mutti. C’était très simple. Il suffisait de changer de langue et les mots n’avaient plus le même sens. Mutti et Mommy désignaient deux personnes différentes. Mommy n'était plus là, mais je n’avais pas pour autant perdu ma mère puisque Mutti était là (...) Je n’étais plus la fille que Mommy avait abandonnée, j'étais celle que Mutti venait d'acquérir. (...) Vous voyez la magie. Langue étrangère, nouvelle identité. (p. 265) ${ }^{17}$

\footnotetext{
${ }^{16}$ Conferência pronunciada em 1994 na Maison des écrivains et de la littérature, em Paris e reunida no livro Désirs et Réalités, de 1995.

17 “É apenas uma explicação, apenas uma história que conto para mim mesma para poder compreender minha vida, para poder dormir à noite: as pessoas transformam suas vidas em história para torná-las compreensíveis, tragáveis. Então, no que diz respeito à língua materna, quando eu tinha seis anos, ela desapareceu. Minha mãe e sua língua em sua boca. Mary-Louise era seu nome - é ainda. E ainda: Mommy, Mom, Mother. Ela foi imediatamente substituída por uma jovem imigrante alemã cujo nome era Maria. Mutter. Mutti. Simples assim. Bastava mudar de língua e as palavras já não tinham mais os mesmos significados. Mutti e Mommy designavam duas pessoas diferentes. Mommy não existia mais, não estava mais lá, mas eu não tinha perdido minha mãe, porque Mutti existia e estava lá. [...] Eu não era mais a
} 
Nessa passagem, há a publicação da experiência traumática que vai influenciar toda a vida artística - e intelectual - de Nancy Huston: o abandono pela mãe, cujo testemunho é, nesse sentido, a narração [Erzählung] de algo que não pode ser esquecido, de algo que deve, portanto, ser lembrado, mas também a impossibilidade de dizer o que deve ser dito. Em outras palavras, um trabalho de rememoração [Eingedenken] e de transmissão [Überlieferung] que, juntos, transformam o passado traumático em um acontecimento que de certa forma resiste ao esquecimento. Como aponta Gagnebin (2011):

\begin{abstract}
Nossa relação ao passado [é] uma exigência simultaneamente epistemológica e ética: pensar a presença, o passado no presente, não em termos de "representação" (représentation, Vorstellung) mas em termo daquilo que [Ricouer] chama de "representança" (représentance, Vertretung), uma relação orientada pelo reconhecimento da dívida que o presente tem em relação ao passado, e pela responsabilidade narrativa e linguística de testemunho que os vivos assumem em relação aos mortos. (p. 159-160)
\end{abstract}

Assumindo algo que pode ser entendido como próximo à "responsabilidade narrativa” de que fala Gagnebin (2011), Nancy Huston transforma a língua em território de enfrentamento do passado (do abandono). Assim, "bastava mudar de língua e as palavras já não tinham mais os mesmos significados”, confessa a autora, indicando que a possibilidade de redenção (libertação) de seu passado traumático viria por meio da repetição (como transformação, iterabilidade) desse passado em outras línguas - por meio da tradução, enfim. Assim compreendida, essa repetição ou tradução indica, portanto, menos uma desistência ou renúncia do que um desejo indecidível de abandonar a ou de abandonar-se à língua materna, como recupera brilhantemente a audaciosa tradução de Alexis Nouss (1997) da Aufgabe benjaminiana: "l'abandon".

Colocando na cena do desejo a cisão íntima (o Unheimlich) divulgada no termo de Benjamin (2008), a escolha de Nouss (1997) leva para um primeiro plano [es setzt über, réléve] a ideia de "dom imputado" (Auf-Gabe) sugerida por Gagnebin (2002), destacando tanto a relação com a lei e com o sagrado que Aufgabe reserva quanto a precariedade própria da tradução em Nancy Huston, cuja tarefa de repetir o trauma em várias línguas indica a privação de uma língua própria, como sugere Shoshana Felman (1999) sobre as vítimas do Holocausto: “o traumatizado é privado de uma língua na qual narrar sua vitimização. A relação entre trauma e história é muda”18 (p. 213). Assim, se a repetição do trauma é não a renúncia do que lembra o trauma, mas o desejo de narrar o trauma, o que se eleva é justamente um monolinguismo em que um desejo resta e faz repetir - desejo ou resto que ganha valor performativo no intraduzível trecho a seguir, também do discurso En français dans le texte (1995): "En allemand, le mot anglais pour enfer signifie... clair. Hell, Hell, Hell, j’ai soudain le droit de le dire. C’est génial” (p. 266).

\footnotetext{
garotinha que Mommy tinha abandonado, era aquela que Mutti tinha acabado de conquistar. [...] Percebe a magia?; língua estrangeira, identidade nova.” (tradução minha)

18، [....] the traumatized are deprived of a language in which to speak of their victimization. The relation between history and trauma is speechless."
} 
No trecho citado, a palavra "Hell”, indecidivelmente inglesa ou alemã, ocupa o lugar central: ao escolher marcá-la com maiúsculas e separar suas ocorrências com vírgulas, Huston atravessa no inglês o alemão, já que, de certa forma, aplica uma regra do alemão (de marcar os substantivos com maiúscula) no inglês ("hell”: substantivo: inferno). Esse atravessamento - ou corte, como sugiro - é justamente aquilo que irá autorizá-la a pronunciar a palavra ("hell”: subs.: inferno), outorgar-lhe o direito sobre a palavra (no sentido religioso de "verbo" para além do de vocábulo, mot), como lemos em "j'ai soudain le droit de le dire" ("eu de repente tinha o direito de dizer"). Porém, esse direito de palavra, essa possibilidade de poder dizer (possibilidade de performance, portanto) macula a língua materna como o corte de uma navalha, como mostrarei mais adiante. Esse aspecto, ainda, é dobrado em virtude do valor performativo que a repetição (do vocábulo [mot]) expõe. Em outras palavras, "Hell" desempenha [performs] a repetição repetindo-se. Errando entre o inglês e o francês, hesitando entre a língua materna e a língua estrangeira, maculando as pretensas fronteiras entre uma e outra, essa repetição aqui sugere o enfrentamento do Unheimlich - esse corte na língua materna e que Nancy Huston reatualiza através de um ritual de comemoração arquivado em seu próprio nome, como a autora sublinha na carta a Leila Sëbbar incluída no volume Lettres parisiennes: histoires d'exil (1986):

Certains amis (dont toi) disent «Nancy » comme la ville et font rimer « Huston » avec «bâton", d'autres prononcent tous les $n$ et vont même jusqu'à aspirer vaillamment le $h$; moi-même j'hésite à dire mon nom avec des sonorités trop anglaises, surtout lorsque je me présente à des inconnus, de peur d'avoir à le répéter quatre ou cinq fois. Il n'est pas facile d'être sûre de son identité quand on ne parvient même pas à la décliner sans atermoiements $!^{19}$

Essa hesitação é o limiar $\left[\right.$ seuil $\left.^{20}\right]$ em que se inscreve (que ex-creve ${ }^{21}$ ), por exemplo, a pintura de 1989 de Dino Valls, De profundis, reproduzida abaixo:

\footnotetext{
19 “Alguns amigos (incluindo você) pronunciam 'Nancy' como o nome da cidade e rimam "Huston” com 'baton', outros pronunciam todos os $n$ 's e chegam mesmo a aspirar valentemente o $h$; quanto a mim, eu mesma hesito em dizer meu nome com sonoridades muito inglesas, sobretudo quando me apresento a desconhecidos - tenho medo de ter de repetir quatro ou cinco vezes. Não é fácil termos certeza de nossa identidade quando sequer conseguimos pronunciá-la sem hesitações.”

${ }^{20}$ Cf. Nouss, 2012a.

${ }^{21}$ A ex-crição é lida por Jean-Luc Nancy como “a existência de tudo que está 'em questão' no texto está fora do texto, acontece fora da escritura” (cf. Nancy, 2003). Nesse sentido, arriscando uma leitura numa chave informada pelo saber da psicanálise, é possível sugerir que a ex-crição ek-siste ao texto, eksistência que manifesta a fundação do limiar, ao mesmo tempo dentro e fora do texto. Em outras palavras, a manifestação linguística da figura jurídica do soberano.
} 


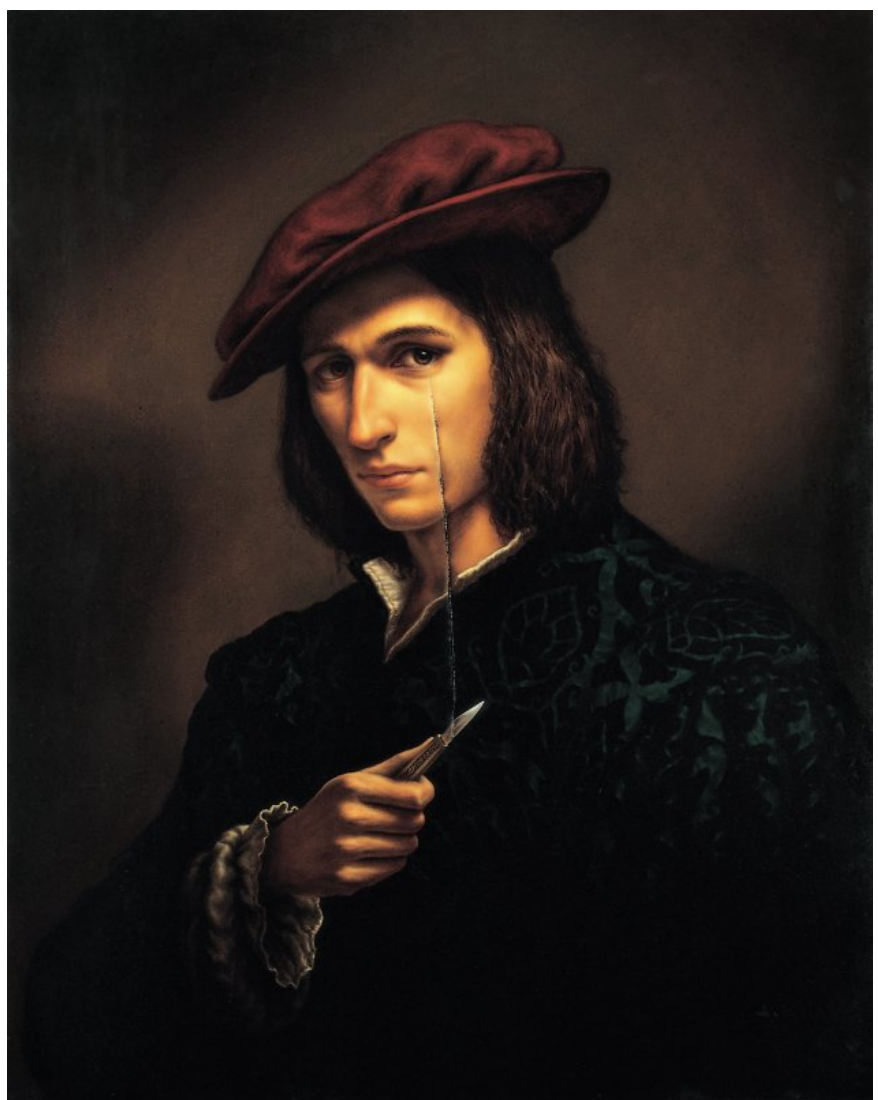

Figura 1. De profundis, Dino Valls, (óleo, 1989)

Na pintura de Valls, há um corte que corrompe, profana e adultera o corpo em pelo menos três níveis: (1) em um nível metafórico, o corte corrompe a obra de arte, o suporte; (2) em um nível metonímico, o corte profana a face do jovem retratado, embora mantenha os olhos intactos e (3) em um nível alegórico, o corte adultera o espaço demarcado pela fronteira que define o "dentro" e o "fora", marcando o limite que, nesse sentido, não pertence nem à obra, ao suporte ( $1^{\circ}$ nível), nem ao fora da obra, ao corpo (do jovem modelo), “objeto” da obra $\left(2^{\circ}\right.$ nível). Esses três níveis, promovendo a fuga do olhar e do suporte (justamente o que Deleuze e Guattari [2008], chamam de desterritorialização), adiam o que seja "original”: o corte faz parte do quadro, da representação do quadro? É o começo do quadro, indica sua leitura? É o quadro, o motivo em torno do qual a representação do quadro gira?

Eminentemente "performativas", tanto a indecidibilidade de Huston no que diz respeito à pronúncia de seu nome quanto a indecidibilidade do corpo verbal "hell” / "Hell" no trecho que lemos e a pintura de Dino Valls funcionam, segundo sugiro, como citação de uma rasura hesitante que, nesse sentido, não anula, mas corta (risca e, em certo sentido, manifesta também uma retirada, um recuo, um ex-crito fora da cena) sua própria possibilidade, a própria possibilidade da interpretação. É esse risco, como corte e cesura tatuado (cicatrizado?) no corpo (do nome, do verbo, do suporte) que sugiro ler como registro da passagem de uma presumida origem ao que sugiro chamar de deviroriginal. 


\subsection{Insucesso e infelicidade da tradução}

Dobrado em fórmulas que necessariamente enfrentam o intraduzível, o espaço da ética em tradução esvazia o sentido (e o lugar antes ocupado) da fronteira entre público e privado, dentro e fora, teoria e prática, corpo e espírito (fronteiras que ameaçariam o sucesso do sagrado projeto democrático que sacraliza a diferença e comemora a exceção), introduzindo na ética o corte e a impossibilidade de um atributo rastreável, como Deleuze (2011) lê na famosa frase de Bartleby, The Scrivener (MELVILLE, 1986), “I would prefer not to”:

fórmula [que] elimina de forma igualmente impiedosa o preferível assim como qualquer não-preferido. Abole o termo sobre o qual incide e que ela recusa, mas também o outro termo que parecia preservar e que se torna impossível. De fato, ela os torna indistintos: cava uma zona de indiscernibilidade, de indeterminação [...] Qualquer particularidade, qualquer referência é abolida. (p. 93-94)

Essa interrupção abrupta, esse esgotamento ou esse buraco que abolem a referência, de acordo com minha hipótese, são índices do espaço dobrado da ética que nomeei devir-ético e dizem respeito à ética $a$, não-lugar da interrupção, do adiamento e do encaminhamento de um suplemento que está, sempre, por vir. Em outras palavras, se o que a tradução informa (performa) é, justamente, a interrupção, o equívoco e o corte, como "comemoram” (no sentido de trazer à memória, isto é, no sentido de ação, de força performativa arquivado em Eingedenken) os excertos de Nancy Huston e a pintura de Dino Valls que apresentei antes, então o que está em jogo é, para além da superação das distinções absolutas (teoria e prática, corpo e espírito, original e tradução) e do apagamento das fronteiras entre essas distinções, uma questão de resposta e de endereçamento que marcam, com efeito, o que chamo de devir-original.

Nesse sentido, a tradução, deslocada pelo performativo de uma ética sempre adiada, emerge como espaço de uma promessa não informada pelo sucesso ou insucesso, felicidade ou infelicidade, mas pela aporia de um insucesso, pela desorientação de uma promessa sempre infeliz: sempre interrompida pelo risco (no duplo sentido do termo) que adia ou rasura seu cumprimento ao mesmo tempo em que ata [bind] ou enxerta, como um "traço-de-união", o cumprimento no performativo, tornando-o, assim, cicatriz ou tatuagem. Hifenização cessante de uma língua sempre do outro, portanto, sempre a construir (em construção), tal é a tarefa por vir da tradução.

Luis Fernando Protásio

luisfprotasio@gmail.com

Doutorando em Linguística Aplicada, UNICAMP

Scientia Traductionis, n.16, 2014 


\section{Referências bibliográficas}

Agambem, Giorgio. Stato di eccezione. Bollati Boringhieri, Torino, 2003.

Arrojo, Rosemary. O signo desconstruído. Campinas: Pontes, 1992.

. Oficina de tradução. A teoria na prática (Série Princípios). São Paulo: Ática, 2007.

Austin, John L. How to do things with words. $2^{\text {nd }}$ Edition. Cambridge, Massachusetts: Harvard University Press, 1975.

Benjamin, Walter. A tarefa-renúncia do tradutor. Tradução de Susana Kampff Lages. In: Castello Branco, Lúcia (org.). A tarefa do tradutor, de Walter Benjamin: quatro traduçõespara o português. Belo Horizonte/MG: FALE-UFMG, 2008, pp. 66-81

Berman, Antoine. L'épreuve de l'étranger. Paris: Gallimard, 1984.

. Pour une critique des traductions: John Donne. Paris: Gallimard, 1995. . A tradução e a letra ou o albergue do longínquo. Tradução Marie-Hélène Catherine Torres, Mauri Furlan e Andréia Guerrini. Rio de Janeiro: 7Letras/PGET, 2007.

CAMPOS, Haroldo. Da tradução como criação e como crítica. In: Metalinguagem. São Paulo: Cultrix, 1976.

CARDozo, Maurício Mendonça. Espaço versus prática da crítica de tradução literária no Brasil. Cadernos de Tradução. v. 1, n. 19, Florianópolis, 2007, p. 205-234.

- O significado da diferença : a dimensão crítica da noção de projeto de tradução literária. Tradução e Comunicação: Revista Brasileira de Tradutores. n. 18, São Paulo, 2009, p. 101-117.

DEÂNGELI, Maria Angélica. Literaturas magrebinas de expressão francesa: o desafio identitário de traduzir o(s) outro(s). Tradução e Comunicação: Revista Brasileira de Tradutores. n. 18, São Paulo, 2012, p. 31-42.

Deleuze, Gilles. Da superioridade da literatura anglo-americana. In: Deleuze, Gilles; PARnET, Claire. Diálogos. Tradução Eloisa Araújo Ribeiro. São Paulo: Escuta, 1998.

. Crítica e clínica. Tradução Peter Pal Perlbart. São Paulo: Editora 34, 2011.

Deleuze, Gilles; Guattari, Félix. Mil Platôs: Capitalismo e esquizofrenia v. 4. Tradução Suely Rolnik. São Paulo: Editora 34, 2008.

DerridA, Jacques. Assinatura Acontecimento Contexto. Tradução Joaquim Torres Costa e Antonio M. Magalhães. In. DerridA, Jacques. Margens: da filosofia. Campinas: Papirus, 1991. p. 349-373.

. Freud e a cena da escritura. In. DERrIDA, Jacques. A escritura e a diferença. Tradução Maria Beatriz Marques da Silva. São Paulo: Perspectiva, 1995. p. 179-226.

. O que é uma tradução "relevante”. Tradução Olivia Niemeyer Santos. Revista Alfa. v. 44, n. esp., São Paulo, 2000, p. 13-44.

. Force of Law: The "Mystical Foundation Of Authority". In.: DERRIDA, Jacques. Acts of religion. (edited by Gil Anidjar). New York: Routledge, 2002. 
. A time for farewells: Heidegger [read by] Hegel [read by] Malabou. Translated by Joseph D. Cohen. In: Malabou, Catherine. The Future of Hegel. Plasticity, Temporality and Dialectic. Translated by Lisabeth During. London \& New York: Routledge, 2005b.

. Gramatologia. Tradução Miriam Schnaiderman e Renato Janine Ribeiro. São Paulo: Perspectiva, Edusp, 2008 [1967].

DÉTIENNE, Marcel. Comparer l'incomparable. Paris: Seuil, 2000.

. Benjamin’s Silence. Critical Inquiry, v. 25, n. 2, Chicago, 1999, p. 201-234.

FELMAN, Shoshana. Benjamin's silence. Critical Inquiry, Vol. 25, No. 2, “Angelus Novus": Perspectives on Walter Benjamin (1999), pp. 201-234. Disponível em http://www.jstor.org/stable/1344200?seq=1\#page_scan_tab_contents. Acesso em 22 maio 2016.

Freud, Sigmund. Recordar, repetir e elaborar (1914). In: Freud, Sigmund. Obras completas, volume 10: Observações psicanalíticas sobre um caso de paranoia relatado em autobiografia: ("O caso Schreber"): artigos sobre técnica e outros textos (1911-1913). Tradução Paulo César de Souza. São Paulo: Companhia das Letras, 2010.

. Totem e tabu (1912). In: Obras completas, volume 11: Totem e tabu, Contribuição à história do movimento psicanalítico e outros textos (19121914). Tradução Paulo César de Souza. São Paulo: Companhia das Letras, 2012.

Gagnebin, Jeanne Marie. Prefácio. In: KampfF-Lages, Susana. Walter Benjamin: Tradução e Melancolia. São Paulo: EDUSP, 2002. p. 13-18.

. A memória, a história, o esquecimento. In: PAula, Adna Candido, Sperber, Suzi Frankl (org.). Teoria literária e hermenêutica ricoeuriana: um diálogo possível. Dourados: UFGD, 2011.

Hall, Stuart. A identidade cultural na pós-modernidade. Tradução Tomaz Tadeu da Silva e Guacira Lopes Louro. 7 ed. Rio de Janeiro: DP\&A, 2002.

Heller-Roazen, Daniel. Ecolalias: sobre o esquecimento das línguas. Tradução Fábio Akcelrud Durão. Campinas: Editora da Unicamp, 2010.

HouAiss, Antônio. Dicionário Houaiss da Língua Portuguesa. $2^{\mathrm{a}}$ ed. São Paulo: Objetiva, 2009.

Huston, Nancy; Leïla Sebbar. Lettres parisiennes: histoires d'exil. Paris : J'ai lu, 1986.

. Désirs et réalités : textes choisis 1978-1994. Paris : Actes Sud, 1995.

. Nord perdu: suivi de Douze France. Paris: Actes Sud, 1999.

. Losing North: Musings on Land, Tongue and Self. Torondo: McArthur\&CO, 2002.

KLEIN-LATAud, Christine. Les voix parallèles de Nancy Huston. TTR: traduction, terminologie, rédaction, v. 9, n. 1, 1996, p. 211-231. Disponível em http://www.erudit.org/revue/ttr/1996/v9/n1/037245ar.html?vue=resume Acesso: 23 jul. 2013.

Melville, Herman. Bartleby, The Scrivener. In.: . Billy Budd and Other Stories (Penguin Classics). New York: Penguin Group, 1986. 
NANCY, Jean-Luc. Exscription, in: The Birth to Presence (trans. Brian Holmes et al.). Stanford, CA: Stanford University Press, 1993a, 319-340.

Nascimento E Silva, Daniel do. Tradução e corpo. Delta [online]. 2009, vol. 25, n. 2, p. 245-266. Disponível em http://www.scielo.br/scielo.php?script=sci_arttext\&pid=S0102$44502009000200002 \& \operatorname{lng}=e n \& n r m=i s o$. Acesso 22 maio 2016.

Nouss, Alexis; LAMI, Lautent. L'abandon du traducteur: prolégomènes à la traduction des “Tableaux parisiennes” de Charles Baudelaire. TTR : traduction, terminologie, rédaction, v. 10, n. 2, 1997, p. 13-69.

. A tradução: no limiar. ALEA, vol. 14, n. 1, Rio de Janeiro, jan-jun 2012a, p. 13-34.

. A árvore e o texto. (trad. Albertina Vicentini e Alice Maria Araújo Ferreira). Traduzires, vol. 1, n. 2, Brasília, 2012b, p. 5-20.

Ricoeur, Paul. Soi-même comme un autre, Paris, Seuil, 1990.

Rodrigues, Cristina Carneiro. A ética da apropriação. Tradução e Comunicação: Revista Brasileira de Tradutores. n. 17, São Paulo, 2008, p. 21-28.

Ronell, Avital. The Telephone Book. Technology, Schizophrenia, Electric Speech. London: University of Nebraska Press, 1989.

SAFATlE, Vladimir. Grande Hotel Abismo: por uma reconstrução da teoria do reconhecimento. São Paulo: Martins Fontes, 2012.

Siscar, Marcos. Jacques Derrida, o intraduzível. In: Revista Alfa, v. 44, n. esp., São Paulo, 2000, p. 59-69.

VAlls, Dino. De profundis. Óleo sobre tela, 1989. Disponível em http://www.dinovalls.com/gal_pic.php?file=102\&page=1. Acesso: 22 maio 2016.

Venuti, Lawrence. Escândalos da Tradução: por uma ética da diferença. Tradução Laureano Pelegrin, Lucinéia Marcelino Villela, Marileide Dias Esquecia e Valéria Biondo. Bauru, SP: EDUSC, 2002.

Veras, Viviane. Por uma ética da criação. Estudos Linguísticos. Anais de Seminários do GEL, v. 26, Campinas, 1997, p. 328-333.

. O eXtrangeiro na língua materna: (não) cobiçar as coisas alheias. Revista Solta a Voz, v. 19, n. 1, Goiânia, 2008, p. 111-124.

- A tradução e sua relação com o inconsciente: transmitir a psicanálise. Tradução em Revista, v. 7, 2009, p. 01-12. 